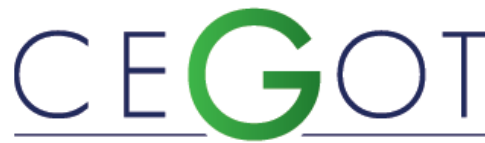

Centro de Estudos de Geografia e Ordenamento do Território
Geografia e Ordenamento do Território, Revista Eletrónica Centro de Estudos de Geografia e Ordenamento do Território http://cegot.org

DUARTE, MIQUEIAS

Universidade Estadual Paulista "Júlio Mesquita Filho" - UNESP — Programa de Pós Graduação em Ciências Ambientais - PCA Av. Três de Março, n. 1435, Alto do Boa Vista. CEP: 18087180, Sorocaba, São Paulo, Brasil miqueiaseng@hotmail.com

SILVA, TATIANA

Universidade Estadual Paulista "Júlio Mesquita Filho" - UNESP

Av. Três de Março, n. 1435, Alto do Boa Vista. CEP: 18087180, Sorocaba, São Paulo, Brasil tatianaacacio1909@gmail.com

\section{Cerqueira, Cláudia}

Fundação Universidade Federal de Rondônia - UNIR, Programa de Pós Graduação em Geografia - PPGG

Campus - BR 364, km 9,5, CEP: 76801-059 - Porto Velho, Rondônia, Brasil. profa.ximenescerqueira@gmail.com

SiLva FilHo, Eliomar

Fundação Universidade Federal de Rondônia - UNIR, Programa de Pós Graduação em Geografia - PPGG

Campus - BR 364, km 9,5, CEP: 76801-059 - Porto Velho, Rondônia, Brasil.

eliomarfilho@uol.com.br

\title{
Pressões Ambientais em Unidades de Conservação: estudo de caso no sul do Estado do Amazonas
}

Environmental pressures in Conservation Units: A case study in the south of the State of Amazonas

Referência: Duarte, Miqueias; da Silva, Tatiana; Cerqueira, Cláudia; Filho, Eliomar (2019). Pressões Ambientais em Unidades de Conservação: estudo de caso no sul do Estado do Amazonas. Revista de Geografia e Ordenamento do Território (GOT), no 18 (Dezembro). Centro de Estudos de Geografia e Ordenamento do Território, p. 108-125, dx.doi.org/10.17127/got/2019.18.005

\section{RESUMO}

As Unidades de Conservação (UCs) são criadas em áreas estratégicas e visam conter ou barrar o avanço do desmatamento, além de proteger a diversidade biológica e cultural. Recentemente foram criadas cinco UCs no sul do estado do Amazonas, Brasil, região que compõe um grande mosaico de áreas protegidas de interesse ecológico e cultural. Entretanto, o interesse por diversos setores da sociedade tem pressionado a redução dessas áreas. Este estudo avaliou as ações antrópicas e reivindicações por exploração de recursos naturais nessa região. Os resultados obtidos mostraram que o desmatamento aumentou em áreas próximas às rodovias e ao longo dos principais rios dentro das UCs. Também verificouse que existem interesses de regularização de imóveis rurais, além da busca por licenciamento para exploração mineral em áreas de proteção integral.

Palavras-chave: Amazônia; Desmatamento; Unidades de Conservação; Proteção Ambiental. 


\section{ABSTRACT}

The Conservation Units (UCs) are created in strategic areas, aimed at containing or barring the progress of deforestation, in addition to protecting biological and cultural diversity. Recently, five UCs were created in the south of the state of Amazonas, Brazil, a region that comprise a large mosaic of protected areas of ecological and cultural interest. However, the interest in several sectors of society has pushed the reduction of these areas. This study evaluated anthropic actions and claims for exploitation of natural resources in this region. The results showed that deforestation increased in areas near the highways and along the main rivers within the UCs. It was also been found that there are interests of regularization of rural properties, in addition to the search for licensing for mineral exploration in areas of integral protection.

Keywords: Amazon; Deforestation; Conservation Units; Environmental Protection.

\section{Introdução}

A Amazônia brasileira foi submetida ao desmatamento extensivo nas últimas quatro décadas, conforme apontam dados do Programa de Cálculo do Desflorestamento da Amazônia - PRODES, entre 1980 e 2004, cerca de $314.000 \mathrm{~km}^{2}$ foram desmatados (INPE, 2018). Na última década, as perdas de floresta têm-se concentrado no "arco de desmatamento" (Kalamandeen et al., 2018), onde uma vasta área de floresta nativa foi removida para o incremento de pastagens e áreas agrícolas (Fearnside, 2017; Rosa et al., 2017).

É conhecido que as perdas de floresta na Amazônia, assim como em outras regiões, podem ter um forte impacto sobre a ciclagem de água (Exbrayat et al., 2017), redução da evapotranspiração, interferindo no regime de chuvas (Zemp et al., 2017), além de aumentar a concentração de poluentes atmosféricos e agravar o efeito estufa (Fearnside, 2009).

Em resposta às mudanças ocorridas pela floresta amazônica no Brasil, grandes áreas naturais ou seminaturais foram delimitadas como "áreas protegidas" (Nogueira et al., 2017), para manter espécies ameaçadas e territórios com alta biodiversidade ("hostpost"), e deter a disseminação do desmatamento e proteger os ecossistemas tradicionais (Marques et al., 2016; Pacheco et al., 2018).

Após o estabelecimento do Sistema Nacional de Unidades de Conservação (SNUC), pela Lei $\mathrm{n}^{\circ}$ 9.985, de 18 de julho de 2000, o Brasil foi o país que mais delimitou Unidades de Conservação (UCs), e a maior parte delas estão localizadas no bioma amazônico (Dias e 
Pereira, 2010). Conta-se que existem cerca de 2.201 UCs que cobrem uma área de 2,54 milhões de $\mathrm{km}^{2}$ no Brasil (MMA, 2018), desse total, cerca de 345 UCs localizam-se na Amazônia, perfazendo uma área de 1.20 milhões de $\mathrm{km}^{2}$ (MMA, 2018). Essas áreas (UCs) cumprem uma série de funções ecológicas cujos benefícios são usufruídos por grande parte da população mundial (Medeiros e Young, 2011; Wandscheer, 2016).

Os serviços ambientais que essas áreas asseguram são múltiplos, destacando a proteção dos recursos naturais (Oliveira et al., 2018), produção de fármacos e cosméticos, proteção de assentamentos humanos contra a ocorrência de desastres naturais (Pacheco et al., 2018), conservação dos recursos pesqueiros (Nogueira et al., 2010), geração de renda com o desenvolvimento do turismo, mitigação da emissão dos gases de efeito estufa e mudanças climáticas (Coe et al., 2013; Pfaff et al., 2015).

O sul do estado do Amazonas, região localizada no arco do desmatamento, passa por forte pressão diante da ocupação do território para o incremento do setor agropecuário (Duarte et al., 2018), em destaque, os municípios de Canutama, Humaitá, Manicoré Novo Aripuanã e Apuí, que tem apresentado altas taxas de desmatamento, conforme dados apresentados pelo PRODES (PRODES, 2018).

Com vista para a preservação da biodiversidade local e frear o avanço do desmatamento em áreas de influência da BR-319, o Governo Federal criou no ano de 2016 cinco Unidades de Conservação no sul do Amazonas (WWF, 2016). Essa região possui alta heterogeneidade ambiental, grande diversidade biológica, e baixa ocupação antrópica, sendo uma das áreas com maior ocorrência de primatas da Amazônia, e também com maior riqueza específica de aves do Brasil (ICMBio, 2016).

Entretanto, as UCs recém-criadas nessa região têm sido palco de várias pressões para a ocupação por outras atividades, principalmente, no que se refere às atividades agropecuária, madeireira e garimpeira. Nesse contexto, este trabalho identificou e mapeou os interesses econômicos e/ou sociais nas Unidades de Conservação, bem como avaliou as taxas de desmatamento nas UCs demarcadas pelo Governo Federal no sul do estado do Amazonas. 


\section{Caracterização da área de estudo}

A área de estudo está localizada no sul do estado do Amazonas, região que compreende quatro municípios: Manicoré, Novo Aripuanã, Apuí, Borba e Maués, situados entre as coordenadas $5^{\circ} 48^{\prime} 46.59^{\prime \prime}$ S. $59^{\circ} 19^{\prime} 18.52^{\prime \prime O}$ e $7^{\circ} 35^{\prime} 8.83^{\prime \prime S}$. $61^{\circ} 4^{\prime} 19.33^{\prime \prime O}$. A principal via de acesso local é a BR-230 (rodovia Transamazônica), que interliga ao estado de Rondônia, no sentido SO e no sentido NE, o estado do Pará e a rodovia AM-174, a qual liga Apuí a Manicoré (Figura 1).

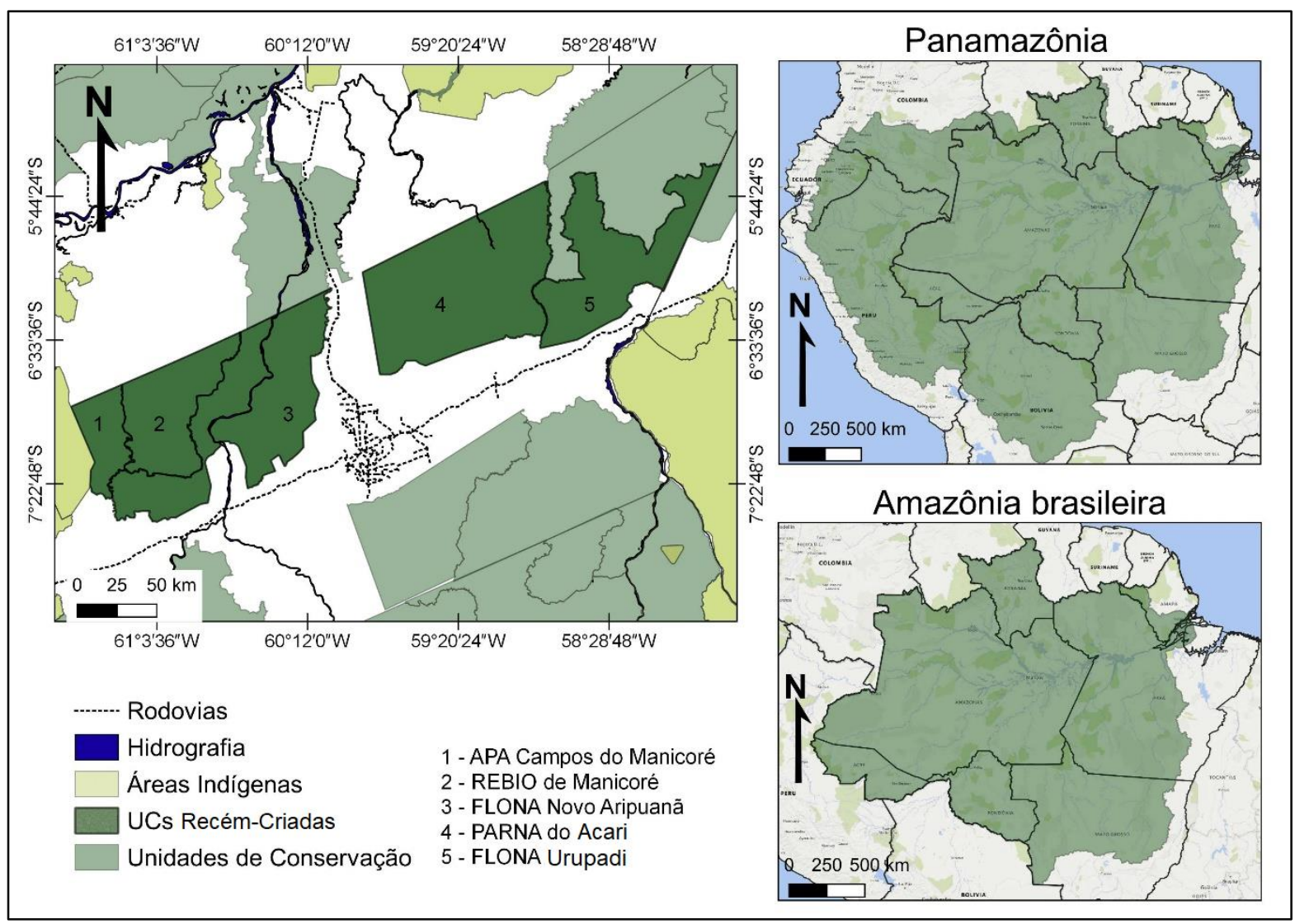

Fig. 1 - Localização das Unidades de Conservação recém-criadas no sul do estado do Amazonas. Fonte: MMA (2018), FUNAI (2018), organizado pelos autores.

As cinco Unidades de Conservação (Tabela 1) perfazem 2,69 milhões de hectares de terras da União. Compõem um grande mosaico de áreas protegidas entre as bacias dos rios Madeira e Tapajós, na área de contenção das frentes de expansão com áreas protegidas e usos alternativos, além de complementarem o grande escudo de áreas protegidas localizado no norte de Mato Grosso, sul do Amazonas e do Pará (ISA, 2017), reforçando 
ações conservacionistas na região da Amazônia brasileira apontada pelo Instituto Chico Mendes de Conservação da Biodiversidade (ICMBio, 2016) como de extrema importância ambiental e de grande potencial de biodiversidade.

Tabela 1 - Unidades de Conservação criadas em 2016.

\begin{tabular}{cccc}
\hline Unidade de Conservação & $\begin{array}{c}\text { Decreto/Ano } \\
\text { Criação }\end{array}$ & Categorias & Área (ha) \\
\hline Parque Nacional do Acari & $\mathrm{s} / \mathrm{n} \mathrm{11/05/2016}$ & Proteção integral & 896.407 \\
Reserva Biológica Manicoré & $\mathrm{s} / \mathrm{n} \mathrm{11/05/2016}$ & Proteção integral & 359.063 \\
Área de Proteção Ambiental Campos de Manicoré & $\mathrm{s} / \mathrm{n} 11 / 05 / 2016$ & Uso sustentável & 152.410 \\
Floresta Nacional Aripuanã & $\mathrm{s} / \mathrm{n} 11 / 05 / 2016$ & Uso sustentável & 751.302 \\
Floresta Nacional Urupadi & $\mathrm{s} / \mathrm{n} \mathrm{11/05/2016}$ & Uso sustentável & 537.228 \\
Total & - & - & 2.696 .410 \\
\hline
\end{tabular}

Fonte: Organizado pelos autores com base em dados do MMA (2019).

O decreto $\mathrm{S} / \mathrm{N}$, que cria as UCs, descreve a importância da implementação de cada unidade. Em suma, o Parque Nacional (PARNA) do Acari foi instituído com o objetivo de proteger a diversidade biológica dos rios Acari, Camaiú, Sucunduri, Abacaxis e de seus afluentes. $\mathrm{Na}$ mesma linha, a Reserva Biológica (REBIO) do Manicoré foi criada para a proteção da diversidade biológica de parte dos rios Manicoré, Manicorezinho, Jatuarana e seus afluentes. Já a Área de Proteção Ambiental (APA) dos Campos de Manicoré foi implementada com intuito de proteger a biodiversidade e ordenar o processo de ocupação na região, em especial, a construção de vicinal de ligação entre o distrito de Santo Antônio do Matupi e a sede do município de Manicoré.

As Flonas do Aripuanã e de Urupadi foram implementadas com o objetivo de promover o manejo de uso múltiplo sustentável dos recursos florestais, a manutenção e a proteção dos recursos hídricos e da biodiversidade, além de apoiar o desenvolvimento de métodos de exploração sustentável dos recursos naturais.

\section{Materiais e Métodos}

Para o desenvolvimento deste estudo, foram obtidos dados sobre as taxas de desmatamento na região para o período de 1997 a 2018, junto à base de dados do Projeto de Estimativa do Desflorestamento da Amazônia/PRODES. Também foram obtidas informações sobre a situação dos imóveis rurais a partir da avaliação de dados disponíveis 
no Cadastro Ambiental Rural/CAR, e dados acerca do requerimento de área para exploração mineral disponibilizado pelo Departamento Nacional de Produção Mineral (DNPM).

Os dados foram reprojetados para o sistema de coordenadas Universal Transversa de Mercator/UTM, Datum SIRGAS 2000, Zona 21S. O processamento e pós-processamento foram realizados com o uso do software QGIS (versão 3.2.3-Bonn), onde foram elaborados mapas temáticos da área de estudo com a sobreposição do plano de informações.

Além disso, foi delimitada a região circunvizinha das Unidades de Conservação em forma de buffer com distâncias de 10, 20 e $30 \mathrm{~km}$ ao redor das UCs com uso da ferramenta Buffer no QGIS, de modo a delimitar as áreas da zona de impacto, conforme estabelecido pela resolução/CONAMA $n^{\circ}$ 13, de 06 de dezembro de 1990, o que possibilitou identificar as áreas de influência direta nas UCs e suas condições atuais de ocupação, constatando as pressões exercidas pela atuação antrópica dentro das UCs e em seu entorno.

\section{Resultados e Discussão}

\subsection{Esforços para revogação ou redução das UCs}

Com a criação das UCs no sul do estado do Amazonas surgiu o discurso de parlamentares e representantes de agricultores do estado com solicitação ao Palácio do Planalto da revisão e/ou revogação dos decretos que criaram as UCs (Paulo, 2017). O argumento dos parlamentares é de que nas áreas de UCs recém-criadas já existiam diversos empreendimentos licenciados, e sem a reversão dos atos haveria prejuízo social/econômico para as famílias e empreendimentos da região (ISA, 2017).

Do mesmo modo, a posição do governo do estado do Amazonas ao afirmar que a criação das UCs poderia prejudicar atividades propostas para a região, inclusive atividades já licenciadas por órgãos ambientais, que incluem atividade de mineração, exploração madeireira e agropastoril (Gesisky, 2017).

Além do mais, os parlamentares e governo do estado questionam que as UCs foram criadas sem os dois requisitos prévios definidos pela Lei no 9.985 de 2000 (realização de estudos técnicos e consulta pública) para a criação das UCs na área (Brasil, 2000). No entanto, o ICMBio apresentou a Nota Técnica $n^{\circ}$ 18/2017 de 13/02/2017 que contestou essas 
afirmações (ICMBio, 2017). Segundo a Lei № 9.985 de 2000, se constatada a importância ecológica de uma área, as UCs podem ser criadas pelo governo mesmo se a população afetada pela criação se opor (Brasil, 2000).

Mesmo negada a anulação do decreto que cria as UCs ou a redução de suas áreas, estes territórios passaram a receber pressões em decorrência da flexibilidade política e dinâmica da BR-230 e rodovia AM-174 entre os estados de Rondônia e Pará (ISA, 2017), área que compreende o avanço do uso consolidado de terras movido pela agropecuária, o que ocasionou diversas pressões ambientais (Duarte et al., 2018).

Estudos desenvolvidos por Costa et al. (2015) e Fearnside (2017) indicam que as unidades de conservação na Amazônia sediam parte da dinâmica territorial da região consolidada do arco do desmatamento. Região em que se constata que as ocupações irregulares determinam as flexibilidades legislativas impostas pelo Poder Público, não como solução, mas como resultado da ausência ou ineficácia de gestão. A ausência de políticas públicas eficazes torna-as vulneráveis às alterações, a partir das interações de uso e a consequente alteração da cobertura vegetal original.

\subsection{0 desmatamento}

Segundo dados do Instituto do Homem e Meio Ambiente da Amazônia (IMAZON), o desmatamento em UCs dobrou na última década. Em 2008, a taxa equivalia a cerca de 7\% de desmatamento total da floresta na Amazônia, enquanto que em 2017 esse percentual foi para 13\% (IMAZON, 2017).

Para Costa et al. (2015) e Fearnside (2017), grande parte das UCs criadas ou implantadas na Amazônia tem sido pressionada por diversas formas de uso e ocupação, geralmente praticadas pelos atores sociais ligados aos setores da pecuária, soja e madeira.

De acordo com Ribeiro e Verissimo (2007), as principais causas para o aumento do desmatamento nas UCs correspondem à ausência de ação por parte do poder público para a efetivação de proteção dessas áreas e às proximidades das UCs com os pólos madeireiros e áreas de consolidação do setor pecuário. 
Não diferente do restante das UCs localizadas na Amazônia brasileira, o desmatamento também avança sobre as UCs recém-criadas no sul do estado do Amazonas, conforme dados apresentados pelo PRODES para o período de 1997 a 2018 (Tabela 2).

Tabela 2 - Desflorestamento em Unidades de Conservação.

\begin{tabular}{cccccc}
\hline Nome & FLONA Aripuanã & REBIO Manicoré & PARNA Acari & FLONA Urupadi & Campos de Manicoré \\
\hline até 1997 & $5,62(0,0 \%)$ & $0,08(0,0 \%)$ & $7,62(0,0 \%)$ & $23,53(0,0 \%)$ & $0,03(0 \%)$ \\
$* 2000$ & $0,65(0,01 \%)$ & $0,00(0,00 \%)$ & $0,21(0,00 \%)$ & $0,00(0,00 \%)$ & $0,00(0,00 \%)$ \\
$* 2001$ & $0,50(0,01 \%)$ & $0,00(0,00 \%)$ & $0,17(0,00 \%)$ & $0,00(0,00 \%)$ & $0,00(0,00 \%)$ \\
$* 2002$ & $0,23(0,00 \%)$ & $0,00(0,00 \%)$ & $0,02(0,00 \%)$ & $0,00(0,00 \%)$ & $0,00(0,00 \%)$ \\
$* 2003$ & $0,41(0,01 \%)$ & $0,00(0,00 \%)$ & $0,01(0,00 \%)$ & $0,00(0,00 \%)$ & $0,00(0,00 \%)$ \\
$* 2004$ & $0,62(0,01 \%)$ & $0,02(0,00 \%)$ & $0,07(0,00 \%)$ & $0,03(0,00 \%)$ & $0,00(0,00 \%)$ \\
$* 2005$ & $0,57(0,01 \%)$ & $0,00(0,00 \%)$ & $0,07(0,00 \%)$ & $0,00(0,00 \%)$ & $0,24(0,02 \%)$ \\
$* 2006$ & $0,14(0,00 \%)$ & $0,00(0,00 \%)$ & $0,18(0,00 \%)$ & $0,16(0,00 \%)$ & $0,00(0,00 \%)$ \\
$* 2007$ & $0,03(0,00 \%)$ & $0,00(0,00 \%)$ & $0,07(0,00 \%)$ & $0,00(0,00 \%)$ & $0,00(0,00 \%)$ \\
$* 2008$ & $0,07(0,00 \%)$ & $0,00(0,00 \%)$ & $0,10(0,00 \%)$ & $0,00(0,00 \%)$ & $0,00(0,00 \%)$ \\
$* 2009$ & $0,36(0,00 \%)$ & $0,27(0,01 \%)$ & $0,00(0,00 \%)$ & $0,00(0,00 \%)$ & $0,26(0,02 \%)$ \\
$* 2010$ & $0,00(0,00 \%)$ & $0,00(0,00 \%)$ & $0,33(0,00 \%)$ & $0,08(0,00 \%)$ & $0,06(0,00 \%)$ \\
$* 2011$ & $0,53(0,01 \%)$ & $0,00(0,00 \%)$ & $0,00(0,00 \%)$ & $0,20(0,00 \%)$ & $0,16(0,01 \%)$ \\
$* 2012$ & $0,18(0,00 \%)$ & $0,00(0,00 \%)$ & $0,00(0,00 \%)$ & $0,11(0,00 \%)$ & $0,00(0,00 \%)$ \\
$* 2013$ & $0,68(0,01 \%)$ & $0,00(0,00 \%)$ & $0,07(0,00 \%)$ & $0,06(0,00 \%)$ & $0,00(0,00 \%)$ \\
$* 2014$ & $0,19(0,00 \%)$ & $0,00(0,00 \%)$ & $0,00(0,00 \%)$ & $4,63(0,09 \%)$ & $0,00(0,00 \%)$ \\
$* 2015$ & $0,32(0,00 \%)$ & $0,28(0,01 \%)$ & $0,00(0,00 \%)$ & $0,54(0,01 \%)$ & $0,00(0,00 \%)$ \\
$* 2016$ & $0,39(0,01 \%)$ & $0,00(0,00 \%)$ & $0,00(0,00 \%)$ & $0,23(0,00 \%)$ & $0,11(0,01 \%)$ \\
$* 2017$ & $1,99(0,03 \%)$ & $0,00(0,00 \%)$ & $0,14(0,00 \%)$ & $0,77(0,01 \%$ & $0,28(0,02 \%)$ \\
$* 2018$ & $2,11(0,03 \%)$ & $0,00(0,00 \%)$ & $0,08(0,00 \%)$ & $1,58(0,03 \%)$ & $0,11(0,01 \%)$ \\
TF (km²) & $7.319,68(97 \%)$ & $3.425,81(95,00 \%)$ & $8.392,07(94 \%)$ & $5.346,24(99 \%)$ & $1.437,57(94 \%)$ \\
TNF(km $\left.{ }^{2}\right)$ & $149,80(1,99 \%)$ & $187,82(5,23 \%)$ & $147,49(1.65 \%)$ & $19,74(0,37 \%)$ & $97.92(6.42 \%)$ \\
Área km² & $7.513,0$ & $3.591,4$ & $8.964,1$ & $5.380,8$ & 1524,1 \\
\hline
\end{tabular}

*Incremento de Desmatamento.; Total de Floresta (TF).; Total Não Floresta (TNF).

Fonte: Organizado pelos autores com base em dados do PRODES (2018).

Observa-se que antes da criação das Unidades de Conservação, pequenas porções de áreas foram desflorestadas, em destaque as áreas pertencentes à FLONA Aripuanã, FLONA Urupadi e nos Campos de Manicoré. A partir da implementação das UCs em 2016, o desmatamento teve continuidade, principalmente sobre a FLONA Aripuanã, FLONA Urupadi e nos Campos de Manicoré. O fato indica que a criação das UCs não impediu que ocorresse supressão de floresta nativa em áreas de proteção integral e sustentável.

As UCs que mais perderam vegetação foram as Flonas Aripuanã e Urupadi, ambas localizadas próximas à Transamazônica e demais vicinais secundárias. Tal constatação, segundo Fearnside et al. (2009), indica que, apesar das próprias reservas resistirem ao desmatamento, as estradas laterais planejadas ao cortá-las proporcionam o avanço do desmatamento para áreas desprotegidas. 
Há forte relação entre as taxas de desmatamento com a distância de estradas na Amazônia Legal, a qual foi observada por diversos autores (Barber et al., 2014; Souza et al., 2017; Jusys, 2018). Nessa região, áreas com distância de 10, 20, 30, 40 e 50 km possuem 55, 38, 15, 12, 9\% a mais de desmatamento do que áreas mais distantes de vicinais (Ferreira, 2001; Ferreira et al., 2005).

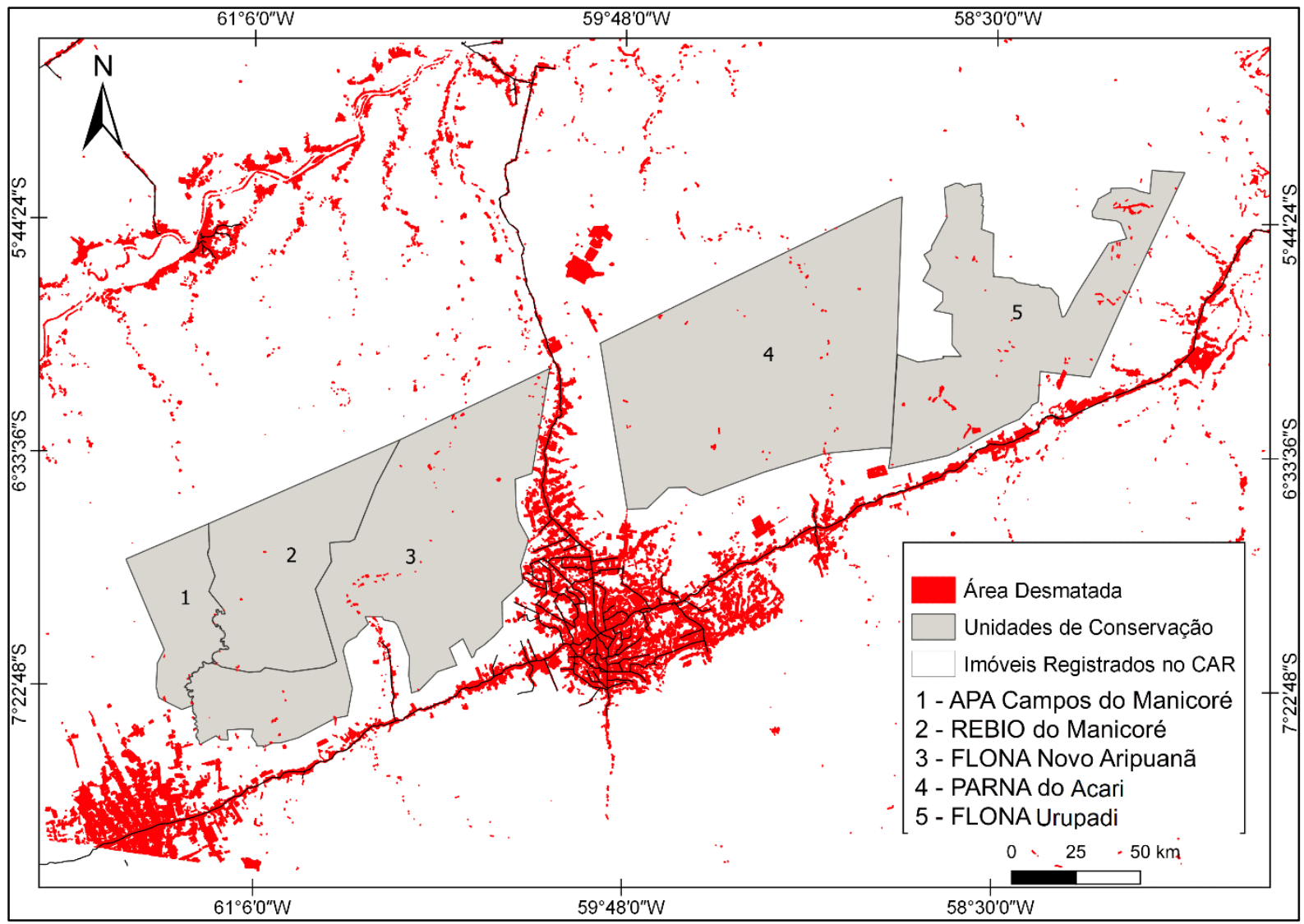

Fig. 1 - Desmatamento acumulado até 2018 nas áreas das UCs.

Fonte: Organizado pelos autores com base em dados do PRODES (2018), MMA (2018).

Esses indicadores enfatizam a importância da fiscalização e monitoramento nas UCs, uma vez que seus limites ficam localizados apenas a 15 km, em média, da BR Transamazônica, ou seja, estão inseridos em uma região de alto impacto ambiental. A facilidade de acesso nesses locais viabiliza a retirada de madeira pelo setor madeireiro, e a partir dessa atividade, surgem as primeiras estradas, mais um dos recursos para os grileiros terem acesso à área. 
A exploração de madeira também fornece recursos para financiar o desmatamento e promover a implantação de pastagem e degradação de áreas (Fearnside, 2010). Dessa forma, a abertura de vicinais propícia a grilagem de terras, seguida pela retirada ilegal de madeira, fato este que impulsiona o desmatamento, como mostra a Figura 2.

Além das rodovias que dão acesso à área, outra forma de entrada dos agentes que causam desmatamento na área corresponde aos rios navegáveis, embora sejam largamente deixados de fora da análise regional dos fatores do desmatamento (Barber et al., 2014). $\mathrm{Na}$ área de estudo, existem fragmentos de áreas desmatadas ao longo dos principais rios que permitem acesso às UCs, o que indica a necessidade de fiscalização pelos órgãos responsáveis também ao longo dos principais rios navegáveis na área.

\subsection{A atuação antrópica em áreas de amortecimento}

A melhor forma de conter o avanço no desmatamento em UCs é o isolamento ou delimitação de zonas de amortecimento (DeFries et al., 2005; Jusys, 2016). A legislação ambiental brasileira dá ênfase à importância da "interface" entre as UCs e o seu entorno, desse modo, a resolução CONAMA n $13 / 90$ e, posteriormente, a Lei do Sistema Nacional de Unidade de Conservação/SNUC (Brasil, 2000) institui as zonas de amortecimento no entorno de UCs. Conforme descrito nessa legislação, apenas as Áreas de Proteção Ambiental e Reserva Particular de Patrimônio Natural estão isentas de zona de amortecimento (Brasil, 2000). Nesse caso, as UCs em estudo devem possuir limites conhecidos de zona de amortecimento.

Nas áreas circundantes das UCs, em um raio de $10 \mathrm{~km}$, qualquer atividade que possa afetar a biota deve ser obrigatoriamente licenciada pelo órgão ambiental competente (Brasil, 1990). Entretanto, como mostra a Figura 3, as principais atividades antrópicas ocorrem em um raio de 10 a $20 \mathrm{~km}$, área fortemente influenciada pelos eixos rodoviários da BR Transamazônica (BR-230).

Observa-se que a BR-230 encontra-se localizada dentro da zona de amortecimento de 10 km, e boa parte da atividade agropecuária desenvolvida no município de Apuí, na região central, e no distrito de Santo Antônio do Matupi, no extremo oeste, incide dentro do raio de $20 \mathrm{~km}$ das áreas de UCs. 


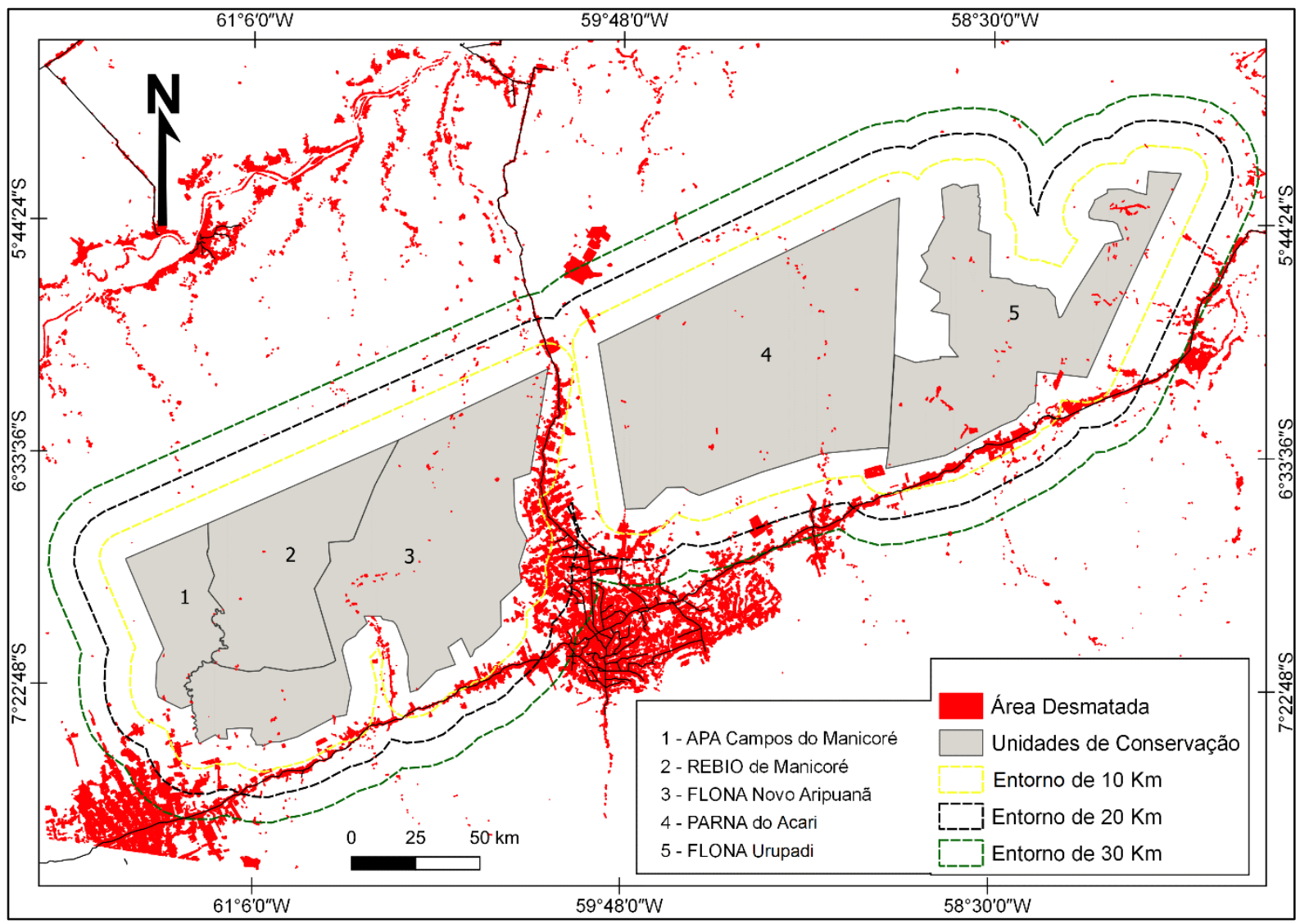

Fig. 2 - Zona de amortecimento sobre Unidades de Conservação.

Fonte: Organizado pelos autores com base em dados do PRODES (2018), MMA (2018).

\subsection{0 registro de imóveis rurais}

Outro fator preocupante diz respeito à sobreposição entre as UCs e imóveis rurais em avaliação junto ao Cadastro Ambiental Rural - CAR (Figura 4). Apesar do CAR não representar um registro fundiário da propriedade rural, esse instrumento vem sendo utilizado para tentar legitimar a ocupação irregular de terras, especialmente, em áreas que incidem em Terras Indígenas e Unidades de Conservação (ISA, 2017).

De acordo com dados do Sistema Nacional de Cadastro Ambiental Rural (SICAR), no município de Novo Aripuanã cerca de 820 hectares submetidos para avaliação no sistema encontram-se sobrepostos às Terras Indígenas e UCs. No município de Manicoré, 48.000,00 hectares submetidos para registro estão localizados em áreas de uso restrito (BRASIL, 2019).

A demanda por registros de imóveis rurais junto ao CAR, apesar de não representar um registro fundiário, permite que grileiros e invasores de terras continuem utilizando esse 
sistema na busca de legitimar ocupações irregulares, ou seja, evidencia a presença de ocupantes sobre áreas de UCs, sejam eles moradores tradicionais, posseiros ou grileiros.

Geralmente, os agentes de registro ilegal estabelecem contratos verbais com os posseiros para explorarem os recursos madeireiros sob o seu controle, o que contribui com a renda e capital para reinvestir no desmatamento da floresta (Pedlowski et al., 2005). Esses agentes têm impulsionado o desmatamento na região amazônica (Ferreira 2001; Fearnside, 2010).

É notória a demanda de registro de imóveis rurais ou posses no entorno e em áreas de domínio das UCs. Embora a lei vigente seja direta ao atribuir ao Poder Público a responsabilidade de fiscalização e a proteção contra qualquer utilização que comprometa a integridade dos atributos naturais das UCs, ainda existe a ocorrência de ocupação irregular nos seus domínios e a tentativa em "legalizar" essas áreas por parte dos ocupantes.

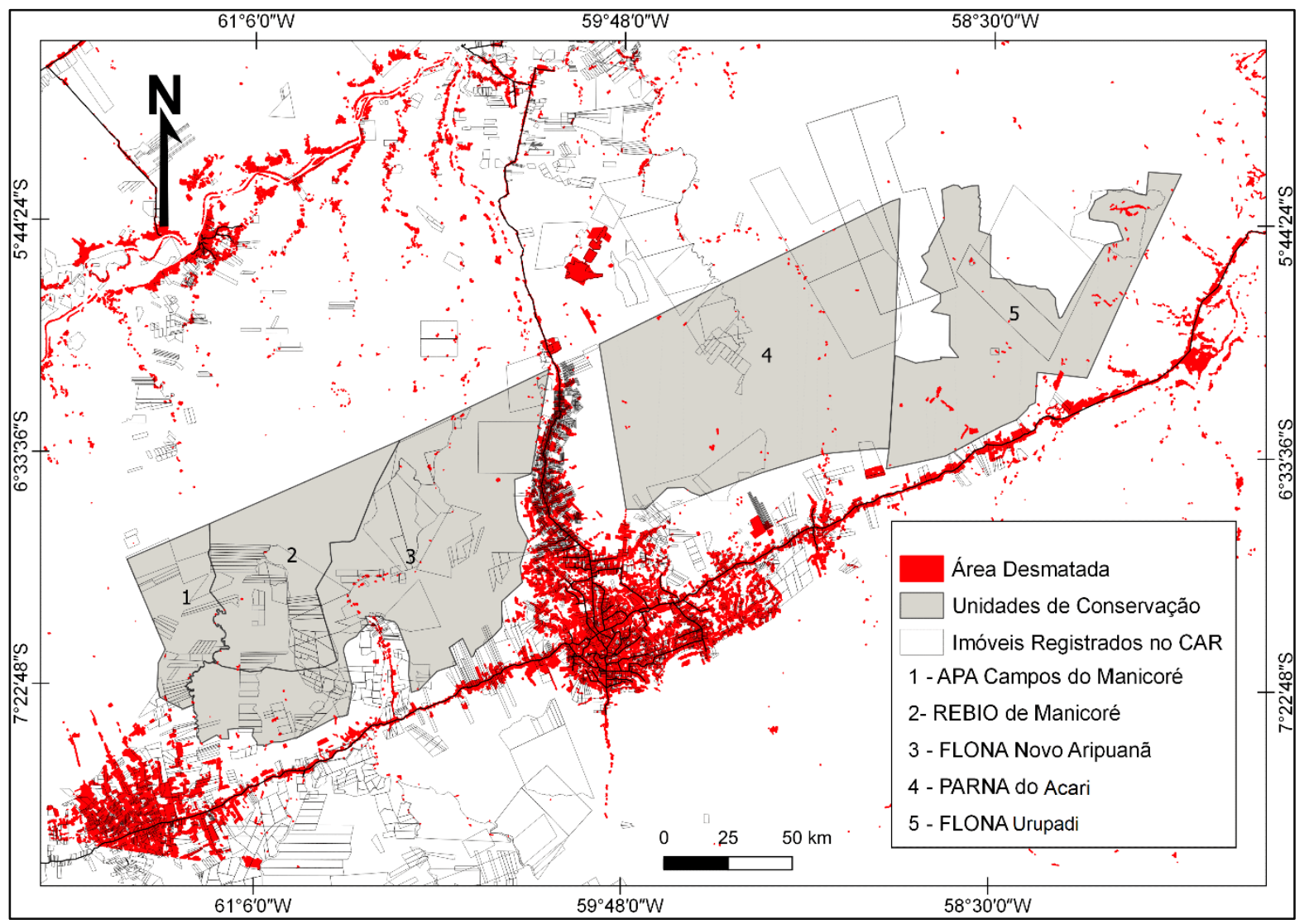

Fig. 3 - A incidência de imóveis rurais em áreas de Unidades de Conservação.

Fonte: Organizado pelos autores com base em dados do PRODES (2018), MMA (2018). 


\subsection{Os interesses por exploração mineral}

Além do interesse dos setores agropecuário e madeireiro na região, existe um considerável interesse por mineradores em função da disponibilidade de recursos na área de estudo. A partir de dados disponibilizados pelo Departamento Nacional de Produção Minerária (DNPM) e sobrepostos aos limites das UCs, verificou-se que há um grande interesse de exploração minerária nos municípios de Manicoré, Novo Aripuanã, Apuí, Borba e Maués, nos quais existem 192 processos minerários incidentes em UCs criadas no sul do Amazonas, que perfazem cerca de $33,19 \%$ do total da área.

O interesse de exploração minerária incide em grande extensão da FLONA Urupadi $(88,10 \%$ do total), do mesmo modo, cerca de 49,30\% do total da APA Campos do Manicoré possuem interesse minerário, seguido por 32,86\% da FLONA Novo Aripuanã. Mesmo sobre o ápice de serem unidades de "proteção integral", existem vários processos com interesse de mineração incidente em seus domínios.

Em relação às fases do processo minerário, cerca de 40,05\% dessas solicitações incidentes em UCs apresentam autorização para pesquisa, 47,24\% com requerimento de pesquisa, 7,95\% com requerimento de lavra garimpeira, 0,05\% em processo de lavra garimpeira e demais 4,63\% com disponibilidade (data de análise em 04/01/2019). Em destaque, o minério de ouro representa cerca de $74 \%$ do interesse nos processos em mineração na área, além deste, o minério de ferro, manganês, areia, nióbio, cassiterita, diamante, cascalho, chumbo, ilmenita e seixo são os demais recursos que buscam legalização para serem explorados nas áreas que incidem sobre as Unidades de Conservação (Figura 5). 


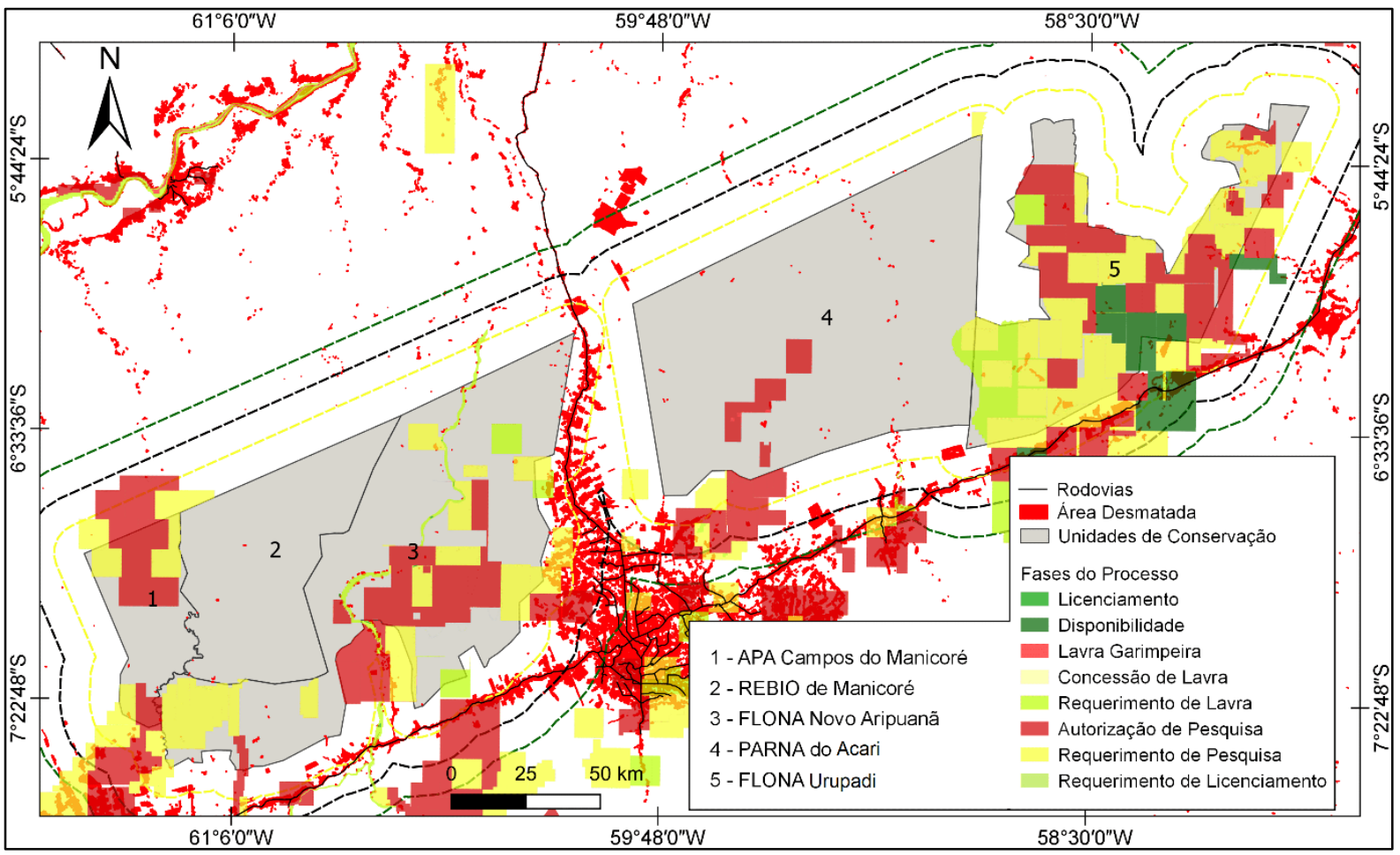

Fig. 4 - Incidência de processos minerários em Unidades de Conservação.

Fonte: Organizado pelos autores com base em dados do PRODES (2018), MMA (2018).

Esse cenário esclarece a atuação do Poder Público frente às UCs, embora sejam implementadas políticas ambientais de modo a proteger uma inestimável riqueza ambiental existente na região. A flexibilidade por parte do Poder Público em consonância com o interesse do capital sobre essas áreas somada às invasões, grilagem, extração mineral, abertura de vicinais clandestinas e avanço do desmatamento evidenciam a fragilidade ambiental que essas áreas possuem.

Considera-se que com a tendência do atual governo brasileiro em flexibilizar a proteção do meio ambiente, uma significativa extensão das UCs recém-criadas no sul do Amazonas pode estar comprometida. As áreas localizadas nas proximidades da rodovia Transamazônica e da rodovia AM-174, que possuem registros efetivados no SICAR, poderão ser as mais atingidas.

\section{Conclusão}

Os resultados obtidos mostraram que as UCs recém-criadas no sul do estado do Amazonas não estão imunes às pressões exercidas por diversos segmentos da sociedade. 0 
desmatamento, as estradas, o requerimento de lavra garimpeira, a busca por registro de imóveis rurais, a ocupação das áreas na zona de amortecimento e a tentativa de diminuição de seus limites são exemplos de pressões diretas observadas sobre as UCs que podem comprometer a função ambiental pela qual essas áreas foram criadas.

Este estudo reforça a necessidade da ação administrativa efetiva que possibilite o gerenciamento adequado das atividades desempenhadas nas UCs, e essas ações devem seguir o Plano de Manejo, no qual estão incluídas normas que devem presidir o uso da área e o manejo dos recursos naturais, inclusive a implantação das estruturas físicas necessárias para a gestão da unidade, conforme estabelecido na Lei do SNUC (2000).

Com o desenvolvimento de ações sistematizadas será possível conciliar o uso e a preservação ambiental sem que prejudique a população que reside em seu entorno e o meio ambiente. Esses dois objetivos, por vez, conflitantes, são alguns dos desafios a serem enfrentados pelo Estado e pela sociedade como um todo.

\section{Agradecimentos}

Os autores agradecem ao Conselho Nacional de Desenvolvimento Científico e Tecnológico (CNPq) e à Coordenação de Aperfeiçoamento de Pessoal de Nível Superior - Brasil (CAPES) pelo auxílio financeiro, e ao Instituto Nacional de Pesquisas Espaciais - INPE pela disponibilidade dos dados.

\section{Referências bibliográficas}

ANDRADE, M. C. A questão do território no Brasil. 2ำ edição. São Paulo: Hucitec. 2004. 135p. ISBN 8527103184

BARBER, C. P.; COCHRANE, M. A.; SOUZA, C. M. JR.; LAURENCE, W. F. Roads. Deforestation, and the mitigating effect of protected areas in the Amazon. Biological Conservation. v. 177. 2014, pp. 203-209. https://doi.org/10.1016/j.biocon.2014.07.004

BRASIL. Lei Federal № 9.985, de 18 de julho de 2000. Regulamenta o art. 225, § $1^{\circ}$, incisos I, II, III e VII da Constituição Federal, institui o Sistema Nacional de Unidades de Conservação da Natureza e dá outras providências. Disponível em: http://www.planalto.gov.br/ccivil 03/LEIS/L9985.htm, Acesso em: Novembro, 2018.

BRASIL. Lei Federal № 9.985, de 18 de julho de 2000. Regulamenta o art. 225, § 10, incisos I, II, III e VII da Constituição Federal, institui o Sistema Nacional de Unidades de Conservação da Natureza e dá outras 
providências. Disponível em: http://www.planalto.gov.br/ccivil 03/LEIS/L9985.htm, Acesso em: Novembro, 2018.

BRASIL. Ministério do Meio Ambiente (MMA). Conselho Nacional do Meio Ambiente (CONAMA). Resolução CONAMA n 13 de 06 de dezembro de 1990. Dispõe sobre normas referentes às atividades desenvolvidas no entorno das Unidades de Conservação. http://www.mma.gov.br/port/conama/res/res90/res1390.html, Acesso em: Dezembro, 2018.

BRASIL., 2019. Sistema Nacional de Cadastro Ambiental Rural - SICAR. Consulta publica. Disponível em: http://www.car.gov.br/\#/, Acesso em: Dezembro, 2018.

COE, M. T..; MARTHEWS, T. R.; COSTA, M. H.; GALBRAITH, D. R.; GREENGLASS, N. L.; IMBUZEIRO, H. M A.; LEVINE, N. M.; MALHI, Y.; MOORCROFT, P. R.; MUZA, M. N.; POWELL, T. L.; SALESKA, S. R.; SOLORZANO, L. A.; WANG. J. Deforestation and climate feedbacks threaten the ecological integrity of south -southeastern Amazonia. Philosophical Transactions of the Royal Society B. 368: 20120155.2013. http://dx.doi.org/10.1098/rstb.2012.0155

COSTA, G.; SILVA, G..; BRAMBILLA, C.; LOBATO, L.; CUNHA, L.; TELES, V.; NUNES, D.; CAVALCANTE, M. Ocupações ilegais em unidades de conservação na Amazônia: o caso da Floresta Nacional do Bom Futuro no Estado de Rondônia/Brasil. Revista de Geografia e Ordenamento do Território, n. 8, 2015, p. 33-49. http://dx.doi.org/10.17127/got/2015.8.003

DEFRIES, R..; HANSEN, A, N. A. C..; HANSEN, M. C. Increasing isolation of protected areas in tropical forests over the past twenty years. Ecological Applications. 15. 2005, pp. $19-26$ https://doi.org/10.1890/03-5258

DUARTE, M. L.; LOCATELLI, M.; SILVA FILHO, E. P.; SILVA, T. A.; 2018. Análise do uso do solo em uma área de bacia hidrográfica localizado na Amazônia central. p, 135-155. 2018. In: Transformação espacial: construção do espaço geográfico. Claudia Araujo Ximenes Cerqueira et al., Organizadores. 1. Ed. - Curitiba, PR: CRV. 162p. https://doi.org/10.24824/978854441895.6

EXBRAYAT, J-F..; LIU, Y. Y..; WILLIAMS, M. Impact of deforestation and climate on the Amazon Basin's aboveground biomass during 1993-2012. Scientific Reports. 7: 15615. https://doi.org/10.1038/s41598-017-15788-6

FEARNSIDE, P, M. Consequências do desmatamento da Amazônia. Scientific American Brasil Especial Biodiversidade. 2010, pp. 54-59.

FEARNSIDE, P, M. Desmatamento na Amazônia: dinâmica, impactos e controle. ACTA AMAZONICA. v. 36, n.3. 2006, pp. $395-400$.

FEARNSIDE, P. Deforestation of the Brazilian Amazon. Environmental Science. 2017, pp. 1-58 https://doi.org/10.1093/acrefore/9780199389414.013.102

FEARNSIDE, P. M. Amazon Forest maintenance as a source of environmental services. Anais da Academia Brasileira de Ciências. v. 80, n. 1. 2008, pp. 101-114.

FEARNSIDE, P. M. Global warming in Amazonia: Impacts and Mitigation. ACT AMAZONICA. v. 39:4. 2009, pp. 1003 - 1012 http://dx.doi.org/10.1590/S0044-59672009000400030

FERREIRA, L. V. Identificação de áreas prioritárias para a conservação da biodiversidade por meio da representatividade das unidades de conservação e tipos de vegetação nas ecorregiões da Amazônia brasileira. In Capobianco, J. P. R. (ed.). Biodiversidade na Amazônia brasileira: avaliação e ações prioritárias para a conservação, uso sustentá-vel e repartição de benefícios. São Paulo, Instituto Socioambiental. 2001, p. 268286.

FERREIRA, L. V.; VENTICINQUE, E.; ALMEIDA, S. O desmatamento na Amazônia e a importância das áreas protegidas. ESTUDOS AVANÇADOS. v. 19, n. 53, 2005. http://dx.doi.org/10.1590/S0103-40142005000100010

GESISKY, J. Corrida por minérios é um dos motivos para reduzir UCs no Amazonas. WWF - BRASIL, 2017. Disponível em: https://www.wwf.org.br/?56302, Acesso em: Novembro, 2018.

GESISKY, J.; PRESOTTI, C. Decisão sobre limites de UCs no sul do Amazonas deve sair em um mês. WWF BRASIL, 2017. Disponível em: https://www.wwf.org.br/?56422, Acesso em: Novembro, 2018.

HEIDRICH, A. L. Espaço e multiterritorialidade entre territórios: Reflexões sobre a abordagem territorial. PEREIRA, Silvia (Org.).; COSTA, Benhur P. (Org.).; SOUZA, E. B. C. (Org.), Teorias e práticas territoriais: análises 
espaço-temporais, Unbral Fronteiras, 2018. Acesso em: Julho, 2018. Disponível em: http://unbral.nuvem.ufrgs.br/base/items/show/4409,

\section{https://doi.org/10.1017/S0376892905002134}

IBGE - Instituto Brasileiro de Geografia e Estatística. Censo 2010. Rio de Janeiro, 2010.

ICMBio - Instituto Chico Mendes de Conservação da Biodiversidade. Resumo do estudo que subsidiou a criação e ampliação das Unidades de conservação no Amazonas. p. 1-4. 2016 . Disponível em: http://www.icmbio.gov.br/portal/images/stories/TEXTOS UC NO SUL DO AMAZONAS 5.pdf

INPE - Monitoramento da Floresta Amazônica Brasileira por Satélite-PRODES. Desmatamento nas Unidades de Conservação. Disponível em: http://www.dpi.inpe.br/prodesdigital/prodesuc.php, Acesso em: Novembro, 2018.

ISA - Instituto Socioambiental. Moat Deforested Conservation Units in the Legal Amazon (2012-2015). 2017. Disponível em: https://imazon.org.br/en/most-deforested-conservation-units-in-the-legal-amazon-20122015/, Acesso em: Novembro, 2018.

ISA - Instituto Socioambiental. Nota Técnica sobre o Projeto de Lei de Redução e Revogação de Unidades de Conservação no Sul do Estado do Amazonas. p. 12. 2017. Disponível em: https://www.socioambiental.org/ptbr, Acesso em: Novembro, 2018.

JUSYS, T. Changing patterns in deforestation avoidance by different protection types in the Brazilian Amazon. PLOS ONE, v. 13, n. 4, 2018. https://doi.org/10.1371/journal.pone.0195900

JUSYS, T. Quantifying avoided deforestation in Pará: Protected areas, buffer zones and edge effects. Journal for Nature Conservation. v. 33. 2016, pp. 10-17 https://doi.org/10.1016/i.jnc.2016.05.001

KALAMANDEEN, M.; GLOOR, E.; MITCHARD, E.; QUINCEY, D.; ZIV, G.; SPRACKLEN, D.; SPRACKLEN, B.; ADAMI, M.; ARAGÃO, L. E. O. C.; GALBRAITH, D. Pervasive Rise of Small-scale Deforestation in Amazonia. Scientific Reports. v. 8. 2018. https://doi.org/10.1038/s41598-018-19358-2

MARQUES, A. A. B..; SCHNEIDER, M..; PERES, C. A. Human population and socioeconomic modulators of conservation performance in 788 Amazonian and Atlantic Forest reserves. PeerJ. 2016.; 4: https://doi.org/10.7717/peerj.2206

MATTAR, E. P. L..; BARROS, T. T. V..; CUNHA, B. B..; Souza, J. F..; SILVA, A. M. C. Federal Conservation Units in Brazil: The Situation of Biomes and Regions. Floresta $e$ Ambiente. v. 25, n.2. 2018 http://dx.doi.org/10.1590/2179-8087.005115

MEDEIROS, R.; YOUNG, C. E. F. Contribuição das unidades de conservação brasileiras para a economia nacional: Relatório Final. Brasília: UNEP-WCMC, 2011. Disponível em: http://www.mma.gov.br, Acesso em: Novembro, 2018.

MMA - Ministério do Meio Ambiente. Amazônia. Componente Projeto Alternativo ao Desmatamento e às Queimadas. 2011. Disponível em: www.mma.gov.br/informma, Acesso em: Novembro, 2018.

MMA - Unidades de Conservação. Dados Consolidados. Acesso em: Novembro, 2018. Disponível em: http://www.mma.gov.br/areas-protegidas/cadastro-nacional-de-ucs/dados-consolidados.html,

NOGUEIRA, C.; BUCKUP, P. A.; MENEZES, N. A.; OYAKAWA, O. T.; KASECKER, T. P.; NETO, M. B. R.; SILVA, J. M. C. Restricted-Range Fishes and the Conservation of Brazilian Freshwaters. PLoS One. v. 5, n. 6. 2010. https://doi.org/10.1371/journal.pone.0011390

NOLTE, C.; AGRAWAL, A.; BARRETO, P. Setting priorities to avoid deforestation in Amazon protected areas: are we choosing the right indicators? Environmental Research Letters. v. 8. 2013. https://doi.org/10.1088/1748$\underline{9326 / 8 / 1 / 015039}$

NOLTE, C.; AGRAWAL, A.; SILVIUS, K. M.; SOARES-FILHO, B. S. Governance regime and location influence avoided deforestation success of protected areas in the Brazilian Amazon. PNAS, 110. 2013, pp. 4956-4961 https://doi.org/10.1073/pnas.1214786110

OLIVEIRA, U.; SOARES-FILHO, B. S.; PAGLIA, A. P.; BRESCOVIT, A. D.; CARVALHO, C. J. B.; SILVA, D. P.; REZENDE, D. T.; LEITE, F. S. F.; BATISTA, J. A. N.; BARBOSA, J. P. P. STEHMANN, J. R.; ASCHER, J. S.; VASCONCELOS, M. F.; 
MARCO, P.; LOWENBERG-NETO, P. FERRO, V. G.; SANTOS, A. J. Biodiversity conservation gaps in the Brazilian protected áreas. Scientific Reports. 7: 9141. https://doi.org/10.1038/s41598-018-22953-y

PACHECO, A.; NEVES, A. C. O.; FERNANDES, Wilson. Uneven conservation efforts compromise Brazil to meet the Target 11 of Convention on Biological Diversity. v. 16.2018 , pp. 43-48. https://doi.org/10.1016/i.pecon.2017.12.001

PAULO, A. Bancada de parlamentares do AM quer reduzir áreas ambientais criadas. Acritica, 2017. Disponível em: https://www.acritica.com/channels/governo/news/bancada-de-parlamentares-do-am-quer-reduzir-areasambientais-criadas, Acessado em: Novembro, 2018.

PEDLOWSKI, M. A., MATRICARDI, E.A.T., SKOLE, D., CAMERON, S.R., CHOMENTOWSKI, W., FERNANDES, C., LISBOA, A. Conservation units: a new deforestation frontier in the Amazonian state of Rondônia, Brazil. Environmental Conservation. 2005, 32 (2): 149-155

PFAFF, A.; ROBALINO, J.; HERRERA, D.; SANDOVAI, C. Protected Areas' Impacts on Brazilian Amazon Deforestation: Examining Conservation - Development Interactions to Inform Planning. PLoS One. 2015.; v. 10, n. 7. https://doi.org/10.1371/journal.pone.0129460

PFAFF, A.; ROBALINO, J.; LIMA, E.; SANDOVAL, C.; HERRERA, L. D. Governance, Location and Avoided Deforestation from Protected Areas: Greater Restrictions Can Have Lower Impact, Due to Differences in Location. World Development. v. 2014, pp. 7-20 https://doi.org/10.1016/j.worlddev.2013.01.011

PRODES - Programa de Monitoramento do Desflorestamento na Amazônia. Desflorestamento nos Municípios da Amazônia Legal para o ano de 2017. Disponível em: http://www.dpi.inpe.br/prodesdigital/prodesmunicipal.php, Acesso em: Novembro, 2018.

RIBEIRO, B.; VERÍSSIMO, A. Padrões e causas do desmatamento nas áreas protegidas de Rondônia. In: FUNDAÇÃO BOTICÁRIO DE PROTEÇÃO A NATUREZA. Natureza e conservação. № 1. Volume 5. Curitiba-PR. SK editora. 2007, pp. $15-26$.

ROCHA, C. F. D.; BERGALLO, H. G..; SLUYS, M. V.; ALVES, M. A. S. Biologia da Conservação: Essências. São Carlos: RiMa, 2006. ISBN 8576560895

SAD - Sistema de Alerta de Desmatamento. Relatório técnico junho de 2018. Disponível em: https://imazon.org.br/PDFimazon/Portugues/transparencia florestal/SAD\%20junho\%202018.pdf, Acesso em: Novembro, 2018.

SMITH, N. J. H.; SCHULTES, R. E. Deforestation and Shrinking Crop Gene-pools in Amazonia. Environmental Conservation, v. 17, n. 3. 1990, pp. 227-234 https://doi.org/10.1017/\$0376892900032367

SOUZA, A. A. A.; PONTES, A. N.; ADAMI, M.; NARVAES, I. S. A Contribuição das Estradas e o Padrão de Desflorestamento e Degradação da Cobertura Florestal no Sudoeste Paraense. Revista Brasileira de Cartografia. v. 69, n. 9. 2017, pp. 1835- 1846.

TOZZO, R. A.; MARCHI, E. C. Unidades de Conservação no Brasil: Uma Visão Conceitual, Histórica e Legislativa. Revista Meio Ambiente e Sustentabilidade. v. 6, n.3. 2014, pp. 508 - 523

VACCHIANO, M. C.; SANTOS, J. W. M. C.; ANGEOLETTO, F.; SILVA, N. Do Data Support Claims That Brazil Leads the World in Environmental Preservation? Environmental Conservation. 2018, pp. 1-3. https://doi.org/10.1017/\$0376892918000371

WANDSCHEER, C. B. Unidades de Conservação e violação dos objetivos legais de proteção. Revista Direito Ambiental e sociedade, v. 6, n. 2. 2016, pp. 201-224.

WWF - Brasil ganha cinco novas áreas protegidas no sul do Amazonas. 2016. Disponível em: https://www.wwf.org.br/informacoes/sala_de imprensa/?uNewsID=52242, Acesso em: Novembro, 2018.

ZEMP, D. C.; Schleussner, C.-F.; Barbosa. H. M. J.; Rammig, A. Deforestation effects on Amazon forest resilience, Geophysical Research Letters. v. 44. 2017, pp. 6182-6190. https://doi.org/10.1002/2017GL072955 